\title{
Los Entremeses de Cervantes como sistema
}

\author{
Elvezio Canonica*
}

\section{INTRODUCCIÓN}

En el lejano 1948 apareció en la Revista de Filología Española un volumen en homenaje al cuarto centenario del nacimiento del «manco de Lepanto». En este tomo voluminoso de más de quinientas páginas, Rafael de Balbín Lucas publicó un artículo sobre el conjunto de los entremeses cervantinos, titulado «La construcción temática de los entremeses de Cervantes» ${ }^{1}$. Dicho trabajo, a nuestro parecer, no ha merecido ser valorado convenientemente ${ }^{2}$. Debajo de la retórica y la ampulosidad muy de la época, el autor propone un esquema de conjunto de los ocho entremeses cervantinos respetando el orden de publicación de la princeps de 1615 que, además de inteligente y novedo-

* Université de Bordeaux 3 (Ameriber).

1. Art. cit., pp. 415-428.

2. Eugenio Asensio, no lo menciona en su Itinerario del entremés (Madrid, Gredos, 1971) y en la introducción a su edición de los Entremeses cervantinos, si bien lo menciona y toma en cuenta, lo despacha en un par de frases, optando por una clasificación «puramente literaria y específicamente teatral» (ed. cit. Madrid, Clásicos Castalia, n. ${ }^{\circ}$ 29, 1970, p. 29). En cambio, el mismo autor no lo menciona en su estudio: «Entremeses», que apareció en el volumen coordinado por J. B. Avalle Arce y E. C. Riley, Suma cervantina, London, Tamesis Books Ltd, 1973, pp. 171-199. Ni siquiera las obras de conjunto sobre el teatro cervantino se sirven de dicho trabajo: Jean Canavaggio en su Cervantès dramaturge: un théâtre à naître (Paris, PUF, 1977), si bien lo menciona en la bibliografía final, no lo utiliza en su libro. Lo mismo ocurre con uno de los libros más recientes, dedicados enteramente a los entremeses cervantinos, el de Vicente Pérez de León, Tablas destempladas. Los entremeses de Cervantes a examen, Madrid, Biblioteca de Estudios Cervantinos, Alcalá de Henares, 2005. Sólo lo menciona dos veces, y de manera marginal, Stanislav Zimic en su ensayo: El teatro de Cervantes, Madrid, Castalia, 1992, mientras que brilla por su ausencia en la reciente entrada (redactada por Vicente Pérez de León) dedicada a los entremeses de Cervantes en el Diccionario filológico de la literatura española. Siglo XVI, Madrid, Castalia, 2009 (s.v.). Tampoco es citado dicho trabajo en la entrada «Cervantes», a cargo de Vicente Pérez de León y Héctor Brioso en la reciente Historia del teatro breve en España, dirigida por Javier Huerta Calvo (Madrid, Iberoamericana, 2008, pp. 143-183). 
so, es sumamente sugerente. Quisiéramos, en lo que sigue, volver sobre el esquema de Balbín para intentar desarrollar las potencialidades que incluye y tratar de mostrar hasta qué punto el conjunto de las ocho piezas forma una unidad temática y estructural que puede arrojar nueva luz sobre el significado de cada una de ellas y de la concepción cervantina del entremés. Intentaremos demostrar, en otras palabras, que la recopilación cervantina, es un paradigma del «sistema», tomando esta noción en su estricto sentido saussuriano ${ }^{3}$.

\section{LA PROPUESTA DE BALBÍN}

El esquema de Balbín, como lo indica el título, es «temático», o sea que se funda en dos núcleos temáticos que él considera como los dos ejes centrales alrededor de los cuales giran las ocho piezas, y que el estudioso define como: 1): «el tema amoroso matrimonial» y 2): «la sátira social». No cabe duda, para cualquier lector de los entremeses de Cervantes, de lo acertado de estas definiciones, que efectivamente constituyen los dos ejes centrales de la poética entremesil cervantina. Sin embargo, y en esto quizás Balbín mismo no se atrevió a ir más lejos, este esquema —insisto, de tipo temático — revela una estructura perfectamente simétrica y especular, que ilumina cada uno de los entremeses de una forma particular y novedosa, postulando, en última instancia, la existencia de una única «obra total», un único entremés en ocho cuadros. Pero ya estamos anticipando: volveremos sobre esta hipótesis en las conclusiones. Hay que reconocerle a Balbín el mérito de haber entrevisto dicha unidad, cuando al proponer su esquema, que reproducimos a continuación, apuntaba hacia las semejanzas y las oposiciones entre los distintos entremeses, pero siempre desde el punto de vista temático ${ }^{4}$ :

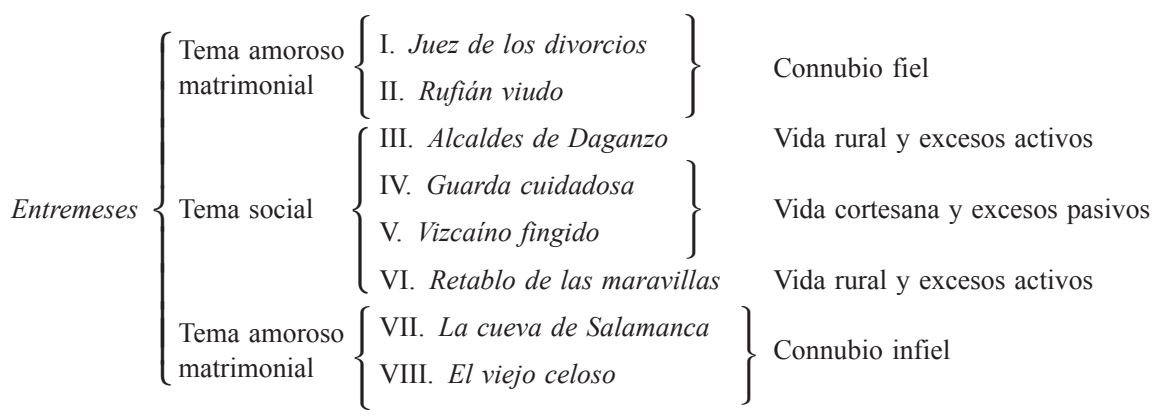

3. «Mais de toutes les comparaisons qu'on pourrait imaginer, la plus démonstrative est celle qu'on établirait entre le jeu de la langue et une partie d'échecs. De part et d'autre, on est en présence d'un système de valeurs et on assiste à leurs modifications. Une partie d'échecs est comme une réalisation artificielle de ce que la langue nous présente sous une forme naturelle. [...] La valeur respective des pièces dépend de leur position sur l'échiquier, de même que dans la langue chaque terme a sa valeur par son opposition avec tous les autres termes.» (F. de Saussure, Cours de linguistique générale, 1916, éd. critique de Tullio de Mauro, Paris, Payot, 1979, p. 125, cursiva nuestra). Para un análisis de esta metáfora del ajedrez, véase el trabajo de Federico Bravo, «El saber del escritor. Por una teoría de la cita», Bulletin hispanique, 1995 (97), pp. 361-374 (en particular, pp. 362-363).

4. El esquema que reproducimos aparece en el citado trabajo de Balbín en la p. 427. 
Balbín, como se puede apreciar, considera los ocho entremeses desde el punto de vista de la unidad temática, respetando el orden de las ocho piezas tal y como apareció en la princeps de 1615. Resulta pues de su esquema que el núcleo temático de la «sátira social» se concentra en los cuatro entremeses centrales de la colección (La elección de los alcaldes de Daganzo, La guarda cuidadosa, El vizcaíno fingido y El Retablo de las maravillas ${ }^{5}$ ), mientras que el tema «amoroso matrimonial» se distribuye en los márgenes de esta estructura de planta central, alternándose entre los dos que abren la colección ( $E l$ juez de los divorcios y El rufián viudo) y los dos que la cierran (La cueva de Salamanca y El viejo celoso). Tenemos pues, a partir de una consideración puramente temática, la revelación de una estructura de tipo: 2-4-2. Apreciamos, de momento, en dicha distribución el afán de buscar una varietas, al no reunir las dos temáticas en dos grupos separados. Al mismo tiempo, dicha varietas supone la reactualización del tema amoroso matrimonial, tratado en los dos primeros entremeses, y vuelto a tratar, de manera preponderante, en los dos últimos. Hay, por lo tanto, también una intención didáctica, puesto que es bien conocida la importancia de la reactualización en el proceso de memorización, siendo uno de los principales «trucos» mnemotécnicos, procedente, en última instancia, del arte del sermón. No se olvide, además, la importancia de la máxima renacentista, procedente de un verso del poeta italiano Serafino Aquilano: «Et per tal variar natura è bella» ${ }^{6}$.

Volviendo al esquema de Balbín, y antes de profundizar en dicha propuesta crítica, debemos mencionar también que ésta ha sido reactualizada en la introducción de una edición moderna del teatro de Cervantes, la que llevaron a cabo Antonio Rey Hazas y Florencio Sevilla Arroyo para la editorial Planeta en 1987. Los dos editores modernos reproducen el esquema de Balbín y muestran, gráficamente, la existencia de estas correspondencias ya anticipadas por el ilustre cervantista del siglo pasado. Sin embargo, no se detienen en comentar dicho esquema ni los ligeros cambios que introducen, lo cual es comprensible en el ámbito de una introducción a un volumen de bolsillo del «Teatro completo» de Cervantes.

Los mismos autores vuelven a reproducir el esquema de Balbín en la entrada «Entremeses [Ocho]» de la reciente «Gran enciclopedia cervantina» ${ }^{8}$, y añaden este comentario: «No obstante, más interés que la hipotética distribución temática en perfecto equilibrio de estas obrillas magistrales tiene la considera-

5. En lo que sigue nos referiremos a los títulos de los entremeses de forma abreviada: Juez (El juez de los divorcios); Rufián (El rufián viudo); Elección (La elección de los alcaldes de Daganzo); Guarda (La guarda cuidadosa); Vizcaíno (El vizcaíno fingido); Retablo (El retablo de las maravillas); Cueva (La cueva de Salamanca); Viejo (El viejo celoso). Todas las citas proceden de la edición de Nicholas Spadaccini, Madrid, Cátedra, Letras Hispánicas, $1990^{8}$.

6. Cf. Patrizia Campana, «"Et per tal variar natura è bella”. Apuntes sobre la variatio en el Quijote», Bulletin of the Cervantes Society of America, 17, 1, 1997, pp. 109-121.

7. Miguel de Cervantes, Teatro completo, estudio, introducción y notas de F. Sevilla Arroyo y A. Rey Hazas, Barcelona, Planeta, 1987, p. L.

8. C. Alvar, A. Alvar Ezquerra y F. Sevilla Arroya (eds.), Gran enciclopedia cervantina, vol. V, Centro de Estudios Cervantinos, Editorial Castalia, 2008 (s.v.). 
ción de los procedimientos técnicos que desenvuelven y de su estética, dado que un análisis de esta índole puede llevarnos a trazar una cierta trayectoria poética que, al margen de su siempre insegura cronología, permita vislumbrar la evolución artística que va desde los entremeses más primitivos hasta los más complejos, en la línea investigadora de Rafael Osuna, cuyos resultados coinciden en buena medida, y harto significativamente, con la ordenación de las piececillas en el volumen de $1615 »^{9}$. La referencia al trabajo de Rafael Osuna, de 1971, es muy importante en el marco de nuestra contribución, puesto que se trata, sin duda, del trabajo más próximo a nuestras preocupaciones, como se puede apreciar desde el título: «La distribución de las obras literarias con referencia a los entremeses de Cervantes ${ }^{10}$. Sin embargo, Osuna no acepta el criterio cronológico de composición: «Pensando en lo que no es más que una costumbre moderna, los cervantistas han aventurado la idea de que los entremeses los vemos hoy en la secuencia en que fueron compuestos; idea que sus propias investigaciones han impugnado de seguida, ya que unos que parecen estar escritos en tal o cual fecha aparecen en la colección impresos antes o después que otros que parecen escritos en fechas anterior o posterior ${ }^{11}$. Con todo, admite Osuna que «si bien se puede fechar algún entremés con precisión, nada se ha dicho definitivo ni sobre los que más se prestan a fecharse, ni mucho menos sobre el resto. Es decir, no puede recusarse totalmente la hipótesis de que fueron publicados en el orden en que se concibieron» ${ }^{12}$. En cambio, el mismo investigador insiste en la relación muy particular que entretienen los entremeses de Cervantes con respecto a su representación y publicación: «hay que tener presente que Cervantes no escribe esos entremeses para imprimirlos y luego representarlos, sino que los imprime porque están escritos y nunca representados. No puede, por ello, conferirles una armonía preestablecida, sino hallársela. Como quien colecciona poemas dispersos y los da a la luz; a ese heteróclito contenido hay que revestirlo de un sentido único que trascienda a todos individualmente; lo dificultoso, claro está, es hallar ese sentido monovalente. En lo que de ningún modo se puede pensar es en un organismo único: ni esto es válido de los entremeses, ni creemos que lo sea de sus comedias ni de sus novelas ejemplares» ${ }^{13}$. Es precisamente dicha «armonía» la que pretendemos buscar en la presente contribución, fundándonos en el esquema de Balbín como punto de partida. A este propósito, hay que señalar que Osuna no ignora dicha propuesta crítica, que define como «meditaciones útiles». Sin embargo, cree que dichas «meditaciones» de Balbín traducen «una problemática no debidamente encauzada»: dicho de otro modo, lo que le reprocha Osuna a Balbín es que «lo que de armónico tiene [su] clasificación es, en suma, la terminología usada» ${ }^{14}$. Con todo, nos parece que su puesta en tela de juicio del esquema de

\footnotetext{
9. Cf. op. cit., p. 4097.

10. Apareció en el Homenaje a W. L. Fichter, Madrid, 1971, pp. 565-574.

11. Cf. op. cit., pp. 565-66.

12. Cf. op. cit., p. 566.

13. Cf. op. cit., p. 567 (cursiva nuestra).

14. Cf. op. cit., p. 570 .
} 
Balbín es algo superficial, sobre todo cuando afirma que «al esquema 2-4-2 propuesto por Balbín, se podría proponer el de 1-6-1; esto es, mientras que el primer entremés y el último versan sobre los problemas matrimoniales, el resto no lo hace, por perogrullesco que esto pueda parecer» ${ }^{15}$. Salta a la vista la incongruencia de dicha afirmación, puesto que el tema matrimonial está presente en varios entremeses, siendo incluso el tema central de Guarda y de Rufián, por lo menos. Hay que reconocer, con todo, que Osuna aprecia el esfuerzo de Balbín: «Porque es esto, más que nada, lo que se trata de aclarar: que Cervantes pudo coordinar sus entremeses impulsado por una motivación reflexiva, todo lo personal e indescifrable que se quiera, per no caprichosa. Aunque no fuera más que por armonizarlas con la deliberación cervantina, estas afirmaciones son dignas del esfuerzo hecho por Balbín» ${ }^{16}$.

Nos concentramos en un primer momento en los cuatro entremeses centrales de la colección, los que tratan ante todo de la «sátira social». Resulta que el mismo esquema especular que hemos observado para el conjunto de la colección vuelve a encontrarse en estos cuatro entremeses, mediante la oposición «corte $v s$ aldea». En efecto, Balbín relaciona los dos entremeses que se sitúan en los dos extremos de este conjunto de cuatro (Elección y Retablo) porque en ellos hay un ambiente aldeano y además se observa lo que el crítico llama «excesos activos», fórmula que los dos editores modernos amplían al añadir el término de «sátira de los excesos activos». Los dos entremeses que quedan en el centro de esta estructura de tipo 1-2-1, o sea Guarda y Vizcaíno, se corresponden en cuanto tratan de la vida urbana de la corte y además, según Balbín, en ellos aparecen los «vicios pasivos», un sintagma al que los editores modernos aplican igualmente el marbete de «sátira».

Volveremos sobre estas fórmulas, pero quisiéramos completar el panorama con la consideración del segundo grupo de cuatro entremeses, los que se sitúan al principio y al final de la recopilación y que tratan el tema amoroso matrimonial. Según Balbín, en este caso, la correspondencia es de tipo recíproco: los dos primeros (Juez y Rufián) tratarían del «connubio fiel», mientras que los dos finales (Cueva y Viejo) presentarían la misma temática a la inversa, o sea el «connubio infiel». Por lo pronto, esta primera profundización del esquema primitivo permite confirmar su pertinencia, y revela ya la existencia de un principio de construcción que informa la disposición de los ocho entremeses. Apreciamos, de entrada, la presencia de un esquema englobante, donde el marco del cuadro es tan importante como su centro. Además, asistimos a una verdadera puesta en abismo, ya que los cuatro entremeses centrales vuelven a disponerse de la misma manera que el conjunto de los ocho. Ahora bien: es menester volver sobre las propuestas de clasificación de Balbín para tratar de profundizar las distintas relaciones que se establecen entre los entremeses, dentro de cada grupo, en un primer momento, y entre los dos grupos en una segunda etapa. 


\section{LOS CUATRO ENTREMESES DE TEMA SATÍRICO-SOCIAL}

Nos concentramos primero en el centro de la colección, o sea en los cuatro entremeses que tratan el tema de la sátira social. Se ha dicho que los dos entremeses centrales, Guarda y Vizcaíno tienen como marco el ambiente cortesano, y que en ellos se lleva a cabo una «sátira de los vicios pasivos», mientras que los dos laterales (Elección y Retablo) se desenvuelven en un ambiente rural y llevan a cabo una «sátira de los excesos activos». A este propósito, los editores modernos añaden al esquema de Balbín una frase para explicar en qué consisten estas sátiras en los entremeses: para Guarda se trataría de la «pasividad del soldado», mientras que para Vizcaíno de la «pasividad de Cristina». Para los dos de ambiente rural, en cambio, no añaden nada a la fórmula de Balbín. Si nos atenemos a la definición que da el mismo Balbín de sus marbetes, notamos que para él tanto Guarda como Vizcaíno «se dedican a censurar la pasividad verbosa y cortesana que en los principios del siglo XVII comenzaba a corroer la firmeza del temple español» ${ }^{17}$, mientras que Elección y Retablo son obras «dirigidas a criticar el irreflexivo accionismo de la vida rural ${ }^{18}$. En consonancia con la mentalidad imperante en la época de redacción de este artículo (1948), Balbín tiende a restar importancia a estas dos piezas, donde la crítica social es sin duda la más mordaz, afirmando que se trata de «obras situadas en lugares secundarios de la serie entremesil» ${ }^{19}$. Ni que decir tiene que esta afirmación suena muy artificial, y hasta contradictoria con la argumentación del propio autor, puesto que nos acaba de demostrar que estas obras ocupan el centro, el corazón, de la recopilación entremesil cervantina. Con todo, y pese a su evidente preferencia otorgada a los entremeses de tema amoroso matrimonial, de ámbito privado y por tanto menos comprometido, como se deduce de las propias palabras de Balbín cuando afirma que: «Cervantes estimó más censurable la corrupción familiar que los vicios externos de la sociedad civil» ${ }^{20}$, el mismo crítico tiene que admitir que su autor «agrupó las cuatro obras de sátira social para atestiguar un hecho común a todos los ocasos políticos: la vitalidad irreflexiva frente a la inteligente pasividad, la idea y la vida separándose y contraponiéndose ${ }^{21}$. Es evidente que nosotros, a nuestras alturas, tenemos que descodificar y desmitificar este lenguaje muy vinculado con una época y un contexto de sobra conocidos. Sin embargo, la intuición de Balbín es certera, pero hay que desarrollarla hasta sus últimas consecuencias. Si por un lado es cierto que en la corte se asiste a una crítica de «los vicios pasivos», dicha crítica no tiene el mismo alcance. En Guarda, se dirige ante todo contra la ingratitud de las instancias del poder, que no recompensan a los que se han batido, como el soldado, arriesgando su propia

17. Art. cit., p. 427 (cursiva nuestra).

18. Ibíd.

19. Art. cit., p. 428.

20. Ibíd.

21. Ibíd. (cursiva nuestra). 
vida, por su patria y su rey. En este caso, la ociosidad es consecuencia de una ingratitud, tanto más llamativa cuanto que el soldado puede comprobar sus servicios militares mediante los documentos fehacientes que va transportando en su canuto, y que sólo le sirven para conseguir una audiencia con el «limosnero mayor». El que prefiera utilizarlos para escribir los billetes amorosos a su fregona es la cifra de toda la sátira cervantina, puesto que se trata de una situación claramente autobiográfica si pensamos en el Cervantes de 1585. En Vizcaíno, muy al contrario, esta misma ociosidad es deliberada, ya que es la de dos muchachos desocupados, que no tienen otra cosa que hacer, para pasar el rato, sino «dar perro muerto» a dos ninfas sevillanas, como lo harán más tarde don Juan y sus compinches en la también sevillana Cal de la Sierpe en El burlador de Sevilla.

Por el lado de la aldea, es también cierto que se critican los «vicios activos», en el sentido de la presunción que acompaña tanto a los labradores ricos de Retablo, en un sentido racial (limpieza) y social (nacimiento legítimo), como a los pretendientes de Elección, en un sentido también racial (orgullo de ser «cristianos viejos» y de legítimo nacimiento) y social (indiferencia y hasta orgullo por su analfabetismo y exaltación de las tareas rústicas) ${ }^{22}$. Dicho de otro modo: la disposición de estos cuatro entremeses neutraliza la oposición guevariana (y de raigambre horaciana) entre corte y aldea, al demostrar que en los dos ámbitos existen prejuicios y actitudes reprobables. Esta neutralización, sin embargo, no hay que interpretarla como una vuelta a una aurea mediocritas, sino como la insistencia en unos valores éticos absolutos, y que no pueden ni deben depender de la circunstancias vitales, ni del entorno social o de la condición de los personajes. Como se echa de ver, también en los entremeses de ambiente rural, Elección y Retablo, encontramos las mismas oposiciones que los relacionan y los iluminan uno a otro. En Retablo, al contrario que en Elección, también aparece el tema amoroso, aunque de forma velada, puesto que una de las dos condiciones para ver el espectáculo de Chanfalla y Chirinos es la de ser hijos legítimos. ¿No habrá aquí una alusión al amor no sometido a las convenciones sociales, al amor libre y natural, que produce los hijos «naturales» y por lo tanto «ilegítimos», y que quedarían por lo tanto excluidos de esta sociedad, al no poder participar en la función? En este sentido, podemos cotejar Retablo con Guarda, ya que así como la elección de Cristina «parece» libre, de la misma manera es ilusoria la libertad de los labradores ricos, quienes están sometidos a los prejuicios sociales de limpieza de sangre y de legitimidad de nacimiento. Por otra parte, entre Elección y Retablo, más allá de las claras simetrías de construcción, puede verse también una progresión: ¿no serán los pretendientes al cargo de alcalde los mismos que aparecen ejerciendo este y otros cargos en Retablo? Dicho de otro modo: Retablo puede leerse como una actualización de la no-elección de Elección, puesto que ahora nos enfrentamos a la situación en la que estos campesinos

22. Sobre Retablo, nos remitimos al amplio estudio de Mauricio Molho, Cervantes: raíces folklóricas, Madrid, Gredos, 1976 (en particular cf. pp. 37-200). 
ignorantes, y hasta orgullosos de serlo, han sido elegidos y tienen que llevar a la práctica sus cargos y administrar la justicia. Son los mismos «cristianos viejos», antes y después de ser elegidos a un cargo administrativo público, al que sólo tenían acceso los que podían presentar la carta de ejecutoria. Hasta cierto punto, pues, Retablo es la continuación y la culminación de Elección, es el mismo entremés, como las dos caras de la misma moneda.

\section{LOS CUATRO ENTREMESES DE TEMA «AMOROSO MATRIMONIAL»}

Si tomamos ahora los entremeses cuyo núcleo temático es el amoroso matrimonial, que ocupan, como queda dicho, el marco de la recopilación, aparecen evidentes correspondencias. Ante todo, cabe subrayar el hecho de que la simetría temática no es estática, sino dinámica. En efecto, pasamos, como bien lo ha visto Balbín, de la defensa del matrimonio fiel (Juez y Rufián) al adulterio, frustrado (Cueva) y consumado (Viejo). Pero en cada caso hay matices significativos: en Juez y Rufián, la defensa del matrimonio fiel no es la misma, ya que en el primer caso a las parejas que piden divorcio se les niega tal derecho porque «es menester que conste por escrito» (p. 109), mientras que en el segundo, muy al contrario, asistimos a unas bodas que se representan en el escenario pero de una forma claramente paródica, puesto que el que se casa es un «rufián», y «viudo» por si fuera poco. Dicha defensa del matrimonio cristiano se da por lo tanto «en negativo», o sea negando el divorcio a parejas claramente «desparejadas» (Juez) y casando a un «incasable», al día siguiente de haberse quedado «viudo» (Rufián). También los dos últimos entremeses presentan un esquema progresivo en la línea del matrimonio infiel: del adulterio frustrado al adulterio consumado. En los dos casos no hay castigo para la mujer adúltera, en pensamiento o en acto, puesto que la crítica se dirige hacia los maridos y a sus debilidades: la credulidad y la superstición (Cueva) y la vejez y los celos obsesivos (Viejo). Podemos apreciar, en esta combinación, una vez más el evangelismo que quizás esté en Cervantes inspirado por la philosophia Christi de Erasmo, puesto que la concepción del adulterio se corresponde con la que aparece en los textos evangélicos. Los dos últimos entremeses, de hecho, pueden leerse como una aplicación literaria y entremesil de las dos maneras con las cuales Jesucristo se enfrenta con el tema del adulterio en los evangelios.

Como se recordará, en el evangelio de San Mateo, Jesucristo insiste ante todo en la identidad entre pensamiento y acción (Mt 5,27-28) ${ }^{23}$, mientras que

23. «Audisti quia dictum est: Non moechaberis. Ego autem dico vobis: Omnis qui viderit mulierem ad concupiscendum eam, iam moechatus est eam in corde suo» («Habéis oído que se dijo: No cometerás adulterio. Pues yo os digo: todo el que mira a una mujer deseándola, ya cometió el adulterio con ella en su corazón» (Mt 5, 27-28) (citamos la traducción de la Biblia de Jerusalén, Madrid, Alianza, 1994). 
en el de San Juan no sólo no condena a la mujer que ha sido sorprendida en pleno adulterio, sino que la salva de la lapidación (Jn 8,2-11) ${ }^{24}$. Por otra parte, la presencia de la superstición y de la magia en Cueva es otro de los temas contra los cuales Erasmo, como es bien sabido, había combatido con gran vehemencia.

Al mismo tiempo, en estos dos últimos entremeses, los dos núcleos temáticos individuados por Balbín se juntan, ya que el adulterio sirve para la sátira social, de forma individual, y es una defensa de la libertad de la mujer a la vez que una condena del patriarcado encarnado en la figura del marido, el señor todopoderoso. Además, en Viejo, el último entremés de la serie, vuelve a aparecer el tema de la diferencia de edad que aparecía en Juez, en el otro extremo de la serie. No será ninguna casualidad que sean precisamente estos dos entremeses los que se cierran al son del mismo estribillo, el de «las riñas de por San Juan/todo el año paz nos dan».

\section{CORRESPONDENCIAS ENTRE LOS DOS GRUPOS DE ENTREMESES}

Este efecto de continuación de un entremés en otro, de hecho, puede apreciarse en varios de ellos, y es aquí donde creemos que el esquema de Balbín podría matizarse y corregirse. En efecto, su principal defecto es el de separar de manera demasiado tajante las dos temáticas, la amorosa y la satírica. De hecho, se aprecian correspondencias también entre los entremeses de tema amoroso matrimonial con los de tema satírico-social: Juez, el entremés que abre la colección, tiene por ejemplo claras consonancias con Elección, por la estructura de desfile de personajes ante un juez o un tribunal. Además, tanto en el uno como en el otro entremés, aparecen cuatro «personajes» (los pretendientes de Elección y las cuatro parejas de Juez). Son entremeses que resumen las formas variadas y distintas de una misma debilidad, que se encarna en individuos y situaciones únicas y particulares. Los otros entremeses no harán sino desarrollar estos temas de forma individual y en una situación única y concreta. Los cuatro casos de parejas que piden el divorcio se vuelven a encontrar, de manera individual y más desarrollada, en los otros entremeses. Mariana y el Vejete son una clara anticipación de la pareja que aparece en el último entremés, Viejo, con la salvedad de ser el viejo «celoso», mientras que el Vejete de Juez es sobre todo «enfadoso», por los achaques debidos a su edad. Entre el soldado y Guiomar (que es nombre de negra en Lope de Rueda), la segunda pareja que desfila ante el juez, se establece una relación estrecha con Guarda, por presentar el soldado, en los dos casos, las mismas características: ocioso, desocupado, sin oficio ni beneficio y un poco poeta.

24. «Dixit autem Iesus: "Nec ego te condemno, vade et amplius iam noli peccare"» («Jesús le dijo: "Tampoco yo te condeno. Vete, y en adelante no peques más"» (Jn, 8,11). 
En este caso concreto, Juez anticipa Guarda, que puede leerse, retrospectivamente, tomando la otra alternativa, la de la elección, por parte de la fregona, del soldado en lugar del sota sacristán. Como Guiomar pasaría hambre pero, con todo, como ella, no se atrevería a «hacer vileza», o sea a prostituirse, para sobrevivir, como lo hace la otra Cristina, la del Vizcaíno. Por eso Guiomar pide el divorcio, y no por falta de amor (dice hablando de la pobreza de su marido: «muérome por remedialle», p. 105). Quizás sea este sentimiento amoroso, todavía presente, el que explica, además de la sátira de la justicia, la suspensión del juicio final y la negación del divorcio. La relación entre el Cirujano y su esposa Aldonza Minjaca también se funda ante todo en una cuestión económica, ya que ella le dice al juez que ha sido engañada al casarse con él, porque él había prometido ascender de cirujano a «médico de pulso», cosa que no hizo. Pero también le reprocha de ser muy celoso («tiene celos del sol que me toca», p. 107), lo cual relaciona este entremés con Viejo, pero también con Guarda por la pobreza. Aldonza Minjaca eligió a un cirujano de la misma manera como Cristina eligió a un sota-sacristán, que también se supone que se habrá quedado en esta situación de inferioridad, que el nombre de su profesión patentiza. En otras palabras, el cirujano corresponde al sota sacristán, en cuanto el primero no ha podido ascender a médico de pulso así como el segundo tampoco a «sacristán de epístola», aunque no por los mismos motivos ya que, de serlo, no hubiese podido casarse. De hecho, la situación de Guiomar y la de Cristina (Guarda) son perfectamente simétricas y muestran el haz y el envés de una misma posibilidad narrativa. En otras palabras: en los dos casos, las parejas habrían terminado pidiendo el divorcio, que se le habría negado: es la serpiente que se muerde la cola, figura del atolladero en el cual están metidos estos personajes, víctimas de los prejuicios sociales. Por fin, el Ganapán, que aparece solo ante el Juez, puede relacionarse con los campesinos de Elección y de Retablo, por presentarse ante todo como «cristiano viejo». Pero también tiene una relación con Vizcaíno ya que se casó un día que estaba borracho (como Quiñones) con una «ninfa» y cumplió la promesa de sacarla del mundo de la prostitución. En este sentido, el Ganapán es el anti-rufián, con lo cual se establece también una relación contrastiva con Rufián. Pero ahora, el Ganapán pide divorcio porque su mujer, aunque no ha reincidido, es pendenciera y colérica («soberbia») con los demás y lo poco que ganan se les va en pagar los juicios, lo cual se enlaza con el tema de la sátira de la justicia de Juez y de Elección, incluso con una alusión a un posible soborno — mediante el «carbón», la materia «diabólica» de la cual estaban embadurnados el sacristán y el barbero en Cueva - un motivo que también aparecía en Elección («no hay sobornos aquí», dice el Bachiller, p. 153). Por lo tanto, el Ganapán representa, hasta cierto punto, la continuación, o la otra cara, de Vizcaíno: ¿qué hubiera ocurrido si Quiñones, en lugar de burlarse de una «mujer errada», la hubiera sacado de aquella condición casándose con ella? De ahí, quizás, la ausencia llamativa de la mujer del Ganapán, que remite a la posibilidad desperdiciada por Quiñones. También notamos que de las cuatro parejas que piden divorcio, en las dos primeras son las mujeres las 
que lo piden, y en las dos siguientes, los maridos. Equilibrio revelador de la igualdad anhelada entre marido y mujer.

Si nos fijamos ahora en los cuatro pretendientes de Elección, notamos que también se establecen otro tipo de relaciones con los demás entremeses. Berrocal es un gran catavinos, lo cual le acomuna con el Quiñones de Vizcaíno (aficionado al vino, pero no olvidemos que es un vizcaíno «fingido»); Humillos se jacta de no saber leer ni escribir y además se sabe de memoria las cuatro oraciones y las reza cada semana cuatro o cinco veces (sátira del cristiano viejo y del cristianismo exterior, como en Retablo y Elección ${ }^{25}$ ); Jarrete se relaciona con Humillos porque, al contrario de aquél, dice que sabe deletrear, lo cual no hace sino amplificar la sátira de la ignorancia de los campesinos y su miedo a ser tachados de cristianos nuevos, por estar asociada la cultura con esta condición de converso, un rasgo común de la mentalidad de la época. Más importante para él parecen ser sus habilidades en las tareas agrícolas (calzar un arado y herrar), y de ser un buen cazador, además de estar orgulloso de su buena salud; Pedro Rana es el que tiene una memoria prodigiosa, y su habilidad consiste en saberse de memorias todas las coplas «del perro de Alba», unas conocidas coplas antijudías, lo cual le relaciona con los labradores de Retablo y de Elección por el tema de la limpieza de sangre. También se establece una relación simétrica y recíproca con la memoria de Humillos, que se aplicaba a las oraciones cristianas. No se olvide que la memoria es una de las tres potencias del alma, y por lo tanto, los dos pretendientes que presumen de ser «cristianos viejos» hacen mal uso de ella, al utilizarla para hacer gala de su intolerancia religiosa (Rana: contra los judíos y los gitanos, que tilda de ladrones ${ }^{26}$ ) y de su práctica mecánica y exterior de la oración cristiana (Humillos). Notamos también, en este mismo entremés, un curioso desfase entre el orden de presentación anunciado por el «tribunal» y el orden efectivo en el cual desfilan los cuatro candidatos: Berrocal-Humillos-JarreteRana vs Humillos-Jarrete-Berrocal-Rana. El cambio de orden produce una nueva progresión: pasamos de Humillos a Jarrete (de una ignorancia asumida y orgullosa a un principio de instrucción, aunque este aprendizaje se presenta como marginal con respecto a los oficios relacionados con las tareas agrícolas y de la labranza, que son la garantía de la identidad del cristiano viejo); de Jarrete a Berrocal, lo cual es una manera de asociar simbólicamente la tierra (Jarrete) con el vino (Berrocal), que, al igual que el pan, es «fruto de la tierra y del trabajo de los hombres», según reza la fórmula litúrgica eucarística. Además, la alusión a la salud del cuerpo de la que hace alarde Berrocal, viene a completar y a confirmar esta alusión a la eucaristía, momento en el cual se repite dicha fórmula (el cuerpo y la sangre de Cristo, simbolizada aquí por el

25. «Humillos alardea de su condición de analfabeta, pues las letras son peligrosas, ya que sus cultivadores pueden caer fácilmente bajo la sospecha de herejía o judaísmo» (Javier Huerta Calvo, «Figuras de la locura en los entremeses cervantinos», en Cervantes y el teatro, Cuadernos de teatro clásico, n. ${ }^{\circ}$ 7, 1992, pp. 55-68 (cit. p. 44).

26. «¿Ellos no son gitanos? Pues adviertan / que no nos hurten las narices» (ed. cit., p. 163). 
vino). Por fin, el paso de Berrocal a Rana permite ante todo mantener a éste en última posición, lo cual le relaciona con Humillos, el primero en presentarse ante el tribunal, en cuanto a la religiosidad desviada (exterior y xenófoba). El cambio de orden conlleva también una doble presentación de los candidatos, indirecta (lo que de ellos dicen los miembros del tribunal) y directa (lo que dicen ellos de sí mismos). Si comparamos lo que dicen de sí los pretendientes con lo que habían dicho de ellos los miembros del tribunal, notamos ciertas diferencias u omisiones. De Berrocal, se decía que era un excelente catavinos, lo cual queda confirmado por él mismo, quien amplía además sus capacidades hasta afirmar que puede reconocer hasta sesenta y seis sabores diferentes; de Jarrete, se nos decía que sabía tirar con un arco, lo cual también él confirma, añadiendo otros particulares (sin hablar de los pájaros, sin embargo); de $\mathrm{Hu}$ millos se decía que sabía remendar zapatos como un sastre, cosa que él no repite, sin duda debido a la fama de ladrones que tenían los sastres; de Rana, finalmente, sabíamos de su memoria excepcional para recordar las coplas antijudías del perro de Alba, de lo cual él no hace mención alguna. Vemos pues que el paso de la presentación indirecta a la directa supone una progresión que puede explicar el cambio de orden: los dos primeros pretendientes confirman lo que se ha dicho de ellos, añadiendo y matizando; los dos siguientes, en cambio, no hablan en absoluto de lo que se ha dicho sobre ellos, y prefieren hablar de otras cualidades menos comprometidas y revelan, al mismo tiempo, todo el alcance de su hipocresía.

Otras correspondencias, más puntuales, pero no menos significativas, se establecen entre los ocho entremeses. Como se recordará, fue precisamente en el «Rastro» donde el sota-sacristán había insultado a Cristina, por sus celos del soldado. Pues bien, como para desquitarla, en Cueva, el estudiante proclama su facultad de guardar silencio con una imagen muy gráfica: «Así pueden matar delante de mí más hombres que carneros en el Rastro, que yo desplegue mis labios para decir palabra alguna» (p. 243). Así mismo, en Cueva, las relaciones con Retablo son numerosas y se deben al motivo del teatro dentro del teatro. Pero no deja de ser significativo que en Cueva, el estudiante utilice precisamente la misma palabra que define al retablo de Chirinos y Chanfalla: «apártense, y verán maravillas» (p. 250). En Cueva aparece también la mención de Escarramán, como supuesto baile diabólico, de cuya habilidad quiere cerciorarse Pancracio cuando le pregunta al barbero: «Dígame, señor mío, pues los diablos lo saben todo, ¿dónde se inventaron todos esos bailes de las Zarabandas, Zambapalo, y Dello me pesa, con el famoso del nuevo Escarramán?» (p. 254).

\section{LAS CUATRO CRISTINAS}

Quizás no sea una casualidad que el nombre de cuatro protagonistas femeninas de estos entremeses (Guarda, Vizcaíno, Cueva y Viejo), sea el mismo: Cris- 
tina $^{27}$. Se habrá notado que se trata de entremeses que pertenecen, según el esquema de Balbín, a los dos núcleos temáticos, equitativamente distribuidos: dos forman parte de la «sátira social» (Guarda y Vizcaíno) y dos del tema «amoroso matrimonial» (Cueva y Viejo). Es necesario, por lo tanto, profundizar en estos cuatro personajes que llevan el mismo nombre, porque pueden revelarse un importante indicio de la unidad «sistemática» de la recopilación entremesil cervantina.

La fregona de Guarda es la que, a pesar de haber sufrido los insultos del sota-sacristán en plena calle (lo cual da lugar a una de las escenas más cómicas de todos los entremeses), acaba casándose con él porque es el único quien le puede garantizar una cierta medianía, mientras que el soldado está sumido en la miseria más negra. La elección del sota-sacristán como marido está por lo tanto claramente marcada por el sello de la ironía mordaz, si consideramos que todas las simpatías de Cervantes van hacia el pobre soldado. Pero, al mismo tiempo, ocurre algo novedoso y absolutamente «revolucionario», como sólo puede darse en un entremés, género de carácter carnavalesco, en el que se puede echar mano del tópico del mundo al revés: los amos de Cristina le permiten elegir a su esposo. Se trata, una vez más, de una postura que va a contracorriente de la práctica matrimonial de la época, totalmente fundada en el matrimonio de interés, tal y como se expone en los demás entremeses. Sin embargo, la libertad de dicha elección queda puesta en tela de juicio, puesto que su principal motor no es el amor, sino la seguridad material, o sea el interés.

Si pasamos ahora a considerar a la Cristina que aparece en Vizcaíno, nos encontramos frente a una situación opuesta, pero cuya reciprocidad contiene una importante enseñanza para entender, a distancia y a contrario, la otra obra. En efecto, en lugar de una fregona, oficio humilde pero honrado, la Cristina de la Guarda es una «ninfa» sevillana, que queda engañada por los dos ociosos cortesanos que son Solórzano y Quiñones, el falso vizcaíno. O sea: pasamos de la Cristina a la que se le permite hacer uso de su libre albedrío (aunque de hecho el determinismo social acaba, significativamente, por anularlo) a una Cristina que es la víctima de unos desocupados pillos. Pero se habrá notado que ambos entremeses se terminan con la misma admisión por parte de los burlados de su derrota (Soldado: "Acepto. Que, donde hay fuerza de hecho/se pierde cualquier derecho», p. 190, y Cristina: «Ahora bien, yo quedo burlada, y, con todo esto, convido a vuestras mercedes esta noche», p. 214), o sea con el perdón hacia sus burladores, en contra de lo que podría esperarse en una comedia o una tragedia, donde el código del honor impediría semejante desenlace.

27. Sobre las criadas que llevan este nombre en el teatro de Cervantes, véase el trabajo de Javier Huerta Calvo, «Cristinas (en torno a las criadas de Cervantes)», en Luciano García Lorenzo (ed.), La criada en el teatro español del Siglo de Oro, Madrid, Fundamentos, 2008, pp. 95-113. El autor también considera a cuatro Cristinas, pero incluye la que aparece en la comedia La entretenida, y no toma en cuenta la de Vizcaíno, quizás porque no la considera una «criada» (en efecto, es una mujer del rumbo). 
Si consideramos ahora a la Cristina que aparece en Cueva, notamos ante todo que es la criada de casa (como la de Guarda), pero ahora cómplice del adulterio frustrado de su ama con el sacristán Reponce ${ }^{28}$, circunstancia que ella querría aprovechar para encontrarse con su amante, el barbero. Esta situación, además de presentar evidentes similitudes con otros entremeses (Guarda por la presencia de un eclesiástico y Viejo por el motivo del adulterio), tiene también una clara conexión con el Quijote, mediante la transposición de las figuras del ama (aquí: Leonarda) y de la sobrina Antonia Quijada (aquí: Cristina, la criada). No será mera casualidad que el galán de Cristina sea precisamente un barbero, y que además tenga el mismo nombre que el del amigo de don Quijote, «maese Nicolás» (aunque después, cuando aparece como «diablo» Cristina le llame «Roque»). De la misma manera, todo nos invita a relacionar al sacristán del entremés con el cura de la novela. En otras palabras, los dos mejores amigos de don Quijote vuelven a aparecer en un entremés, donde reciben un tratamiento entremesil, o sea son presentados de forma carnavalesca, al revés de los que son en la novela. Si el sacristán enamoradizo, máxime después del Concilio de Trento, es la figura obligada para todo clérigo, en Cueva es también la contrafigura a la vez del sota-sacristán de Guarda quien, de haber medrado a sacristán de epístola le habría sido infiel a Cristina, como ya lo insinuaban los insultos que le había espetado en plena calle, y del cura del Quijote, hombre recto y sensato (todo lo contrario del canónigo de Toledo), aquí convertido en amante del «ama» de casa, Leonarda. Y no deja de ser llamativa la presencia, imprevista pero fundamental para el desenlace, de un estudiante «de Salamanca», que no podemos no relacionar con el bachiller Sansón Carrasco, que también, como se recordará, regresaba precisamente «de Salamanca» a la aldea, al principio de la segunda parte del Quijote (II, 2-3) para anunciar la publicación de la primera parte de la novela. La referencia a la segunda parte de la novela, que estaba en gestación, es por otra parte explícita en Cueva, puesto que el estudiante afirma que ha sido víctima «de los lacayos o compañero de Roque Guinarde en Cataluña», el famoso bandolero catalán que aparece en un famoso capítulo de la segunda

28. Este nombre posiblemente pueda asociarse con el «agua de taray» que aparecía en Rufián, y esto debido a un pasaje del tratado de Erasmo Lingua (1525) donde los dos términos aparecen juntos, ya que pertenecen al mismo campo semántico, el de las triacas: «Ay diversas species de cosas de las quales huyen las bestiezuelas ponçoñosas, como es del sahumerio de los yezgos, del galbano, del taray; la mesma virtud tiene el humo y olor del costo y de la yerva que llaman ruypóntico o riponce» ( $\mathrm{La}$ lengua de Erasmo nuevamente romançada por muy elegante estilo, traducción de Bernardo Pérez de Chinchón, Valencia, 1531, ed. de Dorothy Severin, Anejos del Boletín de la Real Academia Española, Anejo XXXI, Madrid, 1975, p. 85, cursiva nuestra). La vinculación entre la Lingua erasmiana y la obra cervantina ha sido puesta en evidencia por Aurora Egido, a propósito del Persiles: «En la Lengua de Erasmo creemos que está presente no sólo el espíritu sino la letra de las teorías desarrolladas por Cervantes en torno al concepto moral de la palabra que se plantea en El Persiles, particularmente en lo que atañe a los casos de Rosamunda y Clodio que parecen exempla para confirmar los postulados erasmistas» (A. Egido, «De La Lengua de Erasmo al estilo de Gracián», en La rosa del silencio. Estudios sobre Gracián, Madrid, Alianza, 1996, p. 29). Sobre esta traducción, véase nuestra ponencia en el último coloquio AISO (Poitiers, julio de 2011): «La traducción española del tratado Lingua por Bernardo Pérez de Chinchón y las ideas lingüísticas de Erasmo» (en prensa). 
parte del Quijote (II, 61). Como en la novela, donde el bachiller es quien consigue vencer a don Quijote en la playa de Barcelona y obligarle a volver a su hogar, y a la razón, en el entremés es el estudiante el que resuelve la situación, al inventar la farsa de la cueva de Salamanca, aprovechando la credulidad y la superstición de Pancracio.

Constatamos, por lo tanto, que la noción de sistema no sólo se limita a las relaciones que se establecen entre los ocho entremeses, sino que incluso desborda estos límites para ensancharse a otras obras de Cervantes. En este sentido, podemos hablar de un verdadero «sistema literario» ${ }^{29}$.

Dicha ampliación del «sistema» de los ocho entremeses al «sistema literario» de la obra cervantina se confirma y se ensancha con la consideración de la última Cristina, la que aparece en Viejo. Como es bien sabido, este entremés es una versión teatral de la novela ejemplar El celoso extremeño, publicada en 1613. Sin embargo, en la novela no aparecía ninguna Cristina, señal de la importancia que desempeña este nombre en los entremeses. Si volvemos ahora al entremés, notamos que la Cristina que allí aparece es la sobrina del matrimonio, o sea que vive en casa de sus tíos, Leonarda y Cañizares (unos nombres claramente alusivos a los del matrimonio de la novela: «Leonora» y «Carrizales»). Por lo pronto, apreciamos el paso de «fregona-ninfa-criada» a «sobrina», lo cual acerca a esta Cristina aun más al Quijote, donde en efecto Antonia Quijada es la «sobrina» de Alonso Quijano. Hay por lo tanto una progresión entre Cueva y Viejo, que no hace sino fortalecer los vínculos de los entremeses con el «sistema literario» cervantino. Con respecto a las tres otras Cristinas, la de Viejo tiene a la vez rasgos comunes y diferenciadores. Como la de Cueva, es cómplice de su ama y tía, a la que incita a cometer el adulterio, al convencerla de seguir las trazas de la vecina Ortigosa, a pesar de las resistencias de su tía. Y ella también quiere participar de la fiesta «carnal», al pedirle a Ortigosa que le traiga a un «frailecico». En este sentido, notamos una progresión con respecto a Cueva, donde la fiesta se presentaba ante todo como un banquete, mientras que la dimensión sexual era más implícita. Con respecto a la fregona de Guarda, la Cristina de Viejo tiene una correspondencia al escoger, para satisfacer su deseo sexual, a un «frailecico» (pese a la ambigüedad acerca del exacto significado de esta palabra ${ }^{30}$ ), mientras que la de Guarda escogió a un «sota-sacristán», y además para casarse públicamente con él. Pero la Cristina de este último entremés también presenta conexiones con la de Vizcaíno, puesto que lo que busca, en cierto sentido, es «dar perro muerto» al viejo Cañizares. Como en aquel entremés, Viejo es también un entremés de «engaño», aunque el engañado esta vez sea el hombre, marido y tío, en lugar de la ninfa sevillana. Dicho de otro modo: hay una inversión de papeles que se

29. Véase el libro de Antonio Prieto, Ensayo semiológico de sistemas literarios, Planeta, Ensayos, 1975.

30. Según E. Asensio puede ser «ambiguamente, el niño pequeño a quien por devoción visten de fraile, y el duende, al cual en Portugal llamaban fraidinho de mão furada y en Italia fraticello» (ed. cit., p. 208, n.8). 
concentra precisamente en el personaje de Cristina, que de engañada (Vizcaíno) se vuelve engañadora (Viejo). Con todo, la actitud claramente transgresora de Cristina se funda en el mucho amor que le tiene a su tía («que quiero yo mucho a mi señora tía, y me muero de verla tan pensativa y angustiada en poder deste viejo», p. 261) por haber sido casada con un viejo y contra su voluntad, como Lorenza misma lo afirma claramente al principio del entremés: «diómele quien pudo, y yo, como muchacha, fui más presta al obedecer que al contradecir» ( $\mathrm{p}$. 258). Una vez más, como en el caso de la primera pareja que se presentaba ante el Juez de los divorcios, la diferencia de edad entre los esposos, causada por la codicia por la dote por parte de la familia de la joven esposa, es el factor social determinante que explica, aunque no justifica, el comportamiento transgresor de esta última Cristina. Y no será mera casualidad que la serie de los ocho entremeses se abra con unas peticiones de divorcios ensartadas, que son negadas por unos jueces tan sólo preocupados por dar largas al asunto y, de esta manera, asegurarse oficio y beneficio, y que se termine con un adulterio consumado, como si fuera ésta la respuesta, el desquite final de todas las parejas «desparejadas» del primer entremés.

Por fin, las claras conexiones que este último entremés establece con $L a$ Celestina («libro, en mi opinión, divi-, / si encubriera más lo huma-», como le había dicho a Sancho el «poeta entreverado» en los versos preliminares de cabo roto que aparecen en la primera parte del Quijote) no hacen sino abrir un poco más el «sistema literario», que se ensancha ahora a lo que se ha venido llamando la «intertextualidad».

Las cuatro Cristinas que aparecen en los entremeses poseen pues rasgos comunes, a la vez por similitud y por contraste, afianzando claramente la idea de «sistema» que hemos venido defendiendo. La Cristina de Guarda escoge al sota-sacristán Pasillas por interés, a pesar de ser maltratada verbalmente por él. Sin embargo, se nota claramente que su afición la lleva hacia el soldado poeta, al que llama «mi señor» y «mi soldado», y a quien le salva la vida cuando se entera de que es asaltado por el sota-sacristán y su amigo Grajales. Cumple pues una obra de caridad y de pacificación, en la recta línea del irenismo erasmiano. La de Vizcaíno es una prostituta burlada por los dos granujas ociosos, a quien perdona invitándolos al banquete final; además, si observamos su reacción ante la prohibición de los coches (de acuerdo con la premática real de 1611), descubrimos en ella una actitud muy valiente y nada hipócrita, puesto que, en lugar de quejarse de ello como lo hace su compañera de oficio Brígida, se alegra de poder por fin «dar la cara», «quitando la ocasión de que ninguno se llame a engaño si nos sirviese, pues nos ha visto» (p. 196). Es una manera, solapada pero transparente, de responsabilizar a los «clientes», o sea los hombres, por sus acciones. No estamos lejos de los famosos versos de sor Juana: «¿O cuál es más de culpar, aunque cualquiera mal haga: la que peca por la paga/o el que paga por pecar?» ${ }^{31}$. En cuanto a la Cristina de Cueva se encuentra en la misma

31. Cf. Sor Juana Inés de la Cruz, Obras escogidas, ed. Juan Carlos Merlo, Barcelona, Bruguera, $1979^{2}$, p. 178 . 
situación subordinada que la de Guarda (criada - fregona), pero a diferencia de aquélla, en lugar de casarse con el barbero, prefiere gozar del amor libre, fuera de los lazos matrimoniales (no se dice, ni aquí ni en el Quijote, si el barbero está casado): su culpa consiste ante todo en encontrarse con su amante en la casa de su amo, pero más culpable aún es su ama, la cual piensa llevar a cabo, en esta misma casa, un verdadero adulterio. Es también Cristina la que siente piedad por el estudiante e insiste para que su ama acoja al «extranjero» en su casa, haciendo prueba de aquella hospitalidad que es de gran importancia, como sabemos, en el contexto evangélico (Mt 25, 35) ${ }^{32}$, y bíblico en general. Y su ama también se deja vencer por este sentimiento de caridad, citando nada menos que un versículo de una epístola de San Pablo: «pero, no te pese amigo, de hacer caridad, que vale para todas las cosas» $(1 \mathrm{Tm} 4,8)^{33}$. Cuando aparecen los «diablos», es Cristina la que se preocupa por saber si son «diablos bautizados» y reconviene a su ama quien pronuncia el nombre de Jesús en presencia de los «demonios». La Cristina de Viejo es sin duda la más desvergonzada de las cuatro, pero su actuación se basa en unos sentimientos caritativos hacia su tía, a quien quiere mucho, y en una situación social claramente injusta, en donde la ley natural es suplantada por la ley del interés económico. Una vez más, Amor es vencido por Interés y ello no puede sino desencadenar la reacción del primero sobre el segundo. Es por ello, quizás, que sólo en Guarda y en Cueva aparece el diminutivo afectuoso de «Cristinica».

Hasta cierto punto, pues, podemos decir de las cuatro Cristinas que en ellas «nomen est omen», puesto que su nombre es la forma femenina del de Cristo, o sea la víctima inocente por excelencia que se sacrifica por el perdón de los pecados del género humano y cuyo mensaje central, como es bien sabido es: «Amarás a tu prójimo como a ti mismo» (Mt 22, 39). No será por lo tanto mera casualidad que en Guarda, a la lectura de la «cédula» que el sota-sacristán le había entregado a la fregona, nos enteramos de que el nombre de pila de la Cristina es, en realidad, «Cristiana de Perrazas ${ }^{34}$.

\section{LAS DOS BODAS Y LOS TRES BANQUETES}

Se habrá notado que, de los ocho entremeses, dos (Rufián y Guarda) se cierran con unas bodas, mientras que tres (Rufián, Vizcaíno y Cueva) se terminan con

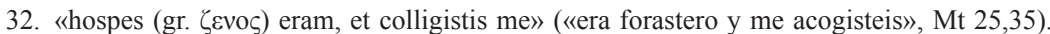

33. «Los ejercicios corporales sirven para poco; en cambio la piedad es provechosa para todo, pues tiene la promesa de la vida, de la presente y de la futura» («pietas - gr. $\varepsilon v \sigma \varepsilon \beta \varepsilon 1 \alpha-a u t e m$ ad omnia utilis est»).

34. Creemos, por tanto, que la elección de este nombre no se debe únicamente a la semejanza de los papeles narrativos, como afirma J. Huerta Calvo: «Estas criadas entremesiles, todas ellas bautizadas con el nombre Cristina, «dulce, con ser de rumbo» — como dice Torrente en La entreteni$d a$-, muestran el alcance que tienen los amores deshonestos cuando se ha producido la quiebra de los honestos y, en general, cuando se impone la ley del placer, mucho más dulce también que la del honor» (art. cit., p. 111). 
sendos banquetes. Rufián es pues el único entremés en el que se combinan los dos motivos: unas bodas escenificadas que van acompañadas por un banquete. En cuanto a las bodas celebradas en Guarda, representan el contrapunto de las de Rufián, puesto que no sólo se lee la «cédula» del novio, es decir que se cumple un acto público, aunque sin intervención de la autoridad religiosa, sino que es la «novia» la que tiene el derecho de elegir entre dos pretendientes, mientras que en Rufián es el «novio» el que elige entre las tres pretendientes, un motivo que es un evidente contrafactum burlesco del famoso episodio homérico de las Tres Gracias, que es el desencadenante, como es bien sabido, de la guerra de Troya y de la composición de la Ilíada.

Un elemento constante en tres de los cuatro entremeses citados es la presencia del vino (además de Rufián, aparece en Vizcaíno y Cueva), mientras que está curiosamente ausente de los festejos nupciales de Guarda, que se limitan a la música. De los tres banquetes en los que se menciona el vino, destaca, por su abundante cantidad, Rufián, puesto que Trampagos le pide a su criado Vademécum: «Parte y trae seis azumbres de lo caro» (p. 130), cantidad que suma unos doce litros. La afición al vino, como es bien sabido, es tópica en los rufianes (piénsese tan sólo en los que aparecen en El buscón). Si nos fijamos con más atención en este entremés, podemos descubrir que la parodia del matrimonio cristiano, que se convierte en una «unión elemental del hombre y de la mujer en una fiesta báquica», como afirma acertadamente J. Casalduero ${ }^{35}$, se construye en oposición con las bodas por excelencia, las de Caná, que encontramos al principio del evangelio de San Juan (Jn 2, 1-11). En el entremés son llamativas y numerosas las referencias al agua en la primera parte, antes de la elección de la Repulida, que es el episodio que desencadena la aparición del vino en abundancia. El agua es un elemento asociado tanto con Trampagos como con la difunta Pericona. El primero, vierte «lágrimas corrientes» (aunque sean las del cocodrilo), mientras que la enfermedad que se llevó a la Pericona hubiera podido curarse con «agua de taray» (p. 117), que sin embargo ella no bebió. Al contrario, parecía tan reacia al agua que la echaba fuera di sí misma por unas «fuentes/en las piernas y en los brazos» (p. 118), que hacía de ella «un Aranjuez «. Al revés de la narración evangélica, donde lo que faltaba era el vino, aquí el elemento faltante es el agua, en particular «el agua de taray» que podría haber salvado a la Pericona y cuya ausencia fue la causa de su muerte (elemento sobre el cual insiste Cervantes: «Y que con agua de taray pudiera/vivir si la bebiera, setenta años», p. 117). Y no será ninguna casualidad que Trampagos pondere los méritos de su favorita mediante la metáfora del «pozo de oro» (p. 122). Pero progresivamente, el agua se va transformando en licor alcohólico: Trampagos define su llanto como «aguardiente» que sale de las «alquítaras» de sus «lanternas» (ojos), y Vademecum añade: «A cuatro lavanderas de la puente/puede dar quince y falta en la colambre;/miren qué ha de llorar, sino agua-ardiente» (p. 123). Finalmente, justo después de haber escogido a su nueva esposa, tenemos la 
gran abundancia del vino (seis azumbres), y del mejor («de lo caro»): como se recordará, en el episodio evangélico, el mayordomo se había asombrado de la excelente calidad del segundo vino, el que Jesucristo había acabado de transformar. El vino que corre en la escena final del entremés, donde se celebran las bodas «paganas», es pues también el producto de una «transformación», aunque de sentido contrario: el «agua de taray» (que faltaba) se transforma en el vino de la boda pagana. De la misma manera, el agua de los humores corporales expulsados tanto por Trampagos («lágrimas») como por la Pericona («sudores», «fuentes», «corrimientos»), y que no han permitido la purificación de la Pericona (¿por qué no se tomó el «agua de taray»?) es la contrapartida del agua de la purificación, que es la que será transformada en vino en Caná ${ }^{36}$. En este sentido, no deja de ser significativo que el nombre de la nueva esposa de Trampagos sea precisamente «la Repulida».

Como se recordará, el episodio evangélico de las bodas de Caná se termina con la aparente y llamativa «desunión» de los lazos de sangre, puesto que Jesús se dirige a su madre llamándola «mujer», una evidente anticipación de la Pasión — en la que el vino que corre será su sangre y el agua la de su costado - donde vuelve a llamar a su madre «mujer» cuando, al confiarla al discípulo a quien amaba, le dice: «Mujer, ahí tienes a tu hijo» $(\mathrm{Jn} 19,26)^{37}$. Bien diferente es el final del entremés, en el que el vino corre de verdad, en una fiesta báquica que celebra, según la ya recordada fórmula de Casalduero, una «unión elemental entre un hombre y una mujer», o sea una boda imposible entre un rufián y una de sus prostitutas.

Pero hay que volver sobre los otros entremeses que presentan un banquete, aunque no esté asociado con unas bodas. Ante todo, notamos que tanto en Vizcaíno como en Cueva, el banquete final es «una cena». El primero se relaciona con Rufián por el contexto de las «ninfas», pero también puede verse, según se ha dicho a propósito de la relación implícita con el Ganapán de Juez, como un banquete nupcial «virtual», por ser una posibilidad narrativa no aprovechada o, mejor dicho, aprovechada en otro entremés (Guarda). En Cueva se acumulan las referencias evangélicas, en particular a las escenas de la Pasión. La alegría de Cristina por recibir a su amante y compartir la comida la compara con «los serones que da el rey el Jueves Santo» (p. 240), una alusión a una costumbre de la época cuando el rey, el día de Jueves Santo, tras lavar los pies a trece pobres, les ofrecía sendas canastas («serones») llenas de regalos. Pero se trata de una comparación ponderativa, ya que la canasta que contiene los manjares que va a compartir con su amante y el de su tía no es la del Jueves Santo, sino «es de Pascua» (ibíd.), o sea el día señalado en el que se podía romper el ayuno de la larga cuaresma, y en el que estaba permitido volver a comer carne (aquí: «empanadas.....manjar blanco y dos capones», ibíd.). Pasamos pues, en Cueva, de la «última cena» del Jueves Santo, a la comida festiva de Pascua de Resurrección.

36. «Había allí seis tinajas de piedra, puestas para las purificaciones de los judíos, de dos o tres medidas cada una. Les dice Jesús: "Llenad las tinajas de agua"» (Jn 2,6-7) (cursiva nuestra).

37. «Mulier (gr. $\gamma v v \alpha \iota)$ ecce filius tuus» (Jn 19,26). 
Este entremés, por tanto, además del vino (también abundante, aunque sólo se limite a una arroba y cuya bondad se pondera con la curiosa expresión: «huele que trasciende», ibíd.) añade un elemento importante, la carne, completando de esta manera el valor eucarístico de la cena. Es por ello que en Guarda no hay banquete, a pesar de celebrarse las bodas: porque allí las bodas no son paródicas, sino reales y fruto de una «libre elección» de los novios.

Una vez más, apreciamos el tratamiento cervantino del «mundo al revés», propio del entremés: además de claras parodias literarias, aparecen también unas referencias, más solapadas, pero sensibles, al contexto evangélico, en particular a los motivos de la boda y del banquete, o sea a dos sacramentos de la Iglesia Católica: el matrimonio y la eucaristía. Además, no se olvide que en el contexto de la época estaba bien presente en las mentes la metáfora de las «bodas místicas» entre Cristo y su esposa, la Iglesia.

\section{CONCLUSIÓN: EL SISTEMA, LA CONNOTACIÓN Y LA ROSA}

Atando cabos, podemos volver a nuestra intuición inicial, inspirada por el sugerente esquema de Balbín, y preguntarnos hasta qué punto los ocho entremeses pueden leerse como una figura literaria de lo que el lingüista suizo Ferdinand de Saussure, a principios del siglo XX, al referirse a la lengua (langue) definió como «sistema». Como se recordará, de Saussure insiste en el hecho de que la lengua es un organismo diferencial, virtual, que sólo existe «en negativo», o sea que sólo puede definirse en relación con los otros elementos que lo componen. El lingüista suizo demuestra como la lengua es un sistema en el que todo es relación, en el cual el mínimo cambio de un elemento influye en el equilibrio de todo el conjunto. De ahí la luminosa comparación con el juego del ajedrez, en el que cada pieza movida hace cambiar todo el conjunto de la partida ${ }^{38}$. Es así como podemos considerar el conjunto de los ocho entremeses cervantinos, que se iluminan uno con otro, explorando las distintas posibilidades ofrecidas por el sistema, al cambiar y sustituir una situación entrevista en una pieza y proponer su continuación en otra pieza, mostrando la cara y la cruz de la misma moneda. El resultado es el de una «obra total», un único gran «entremés» en ocho «cuadros» que explora las distintas posibilidades narrativas en todas sus potencialidades. El hecho de que el esquema temático de Balbín sea también, y al mismo tiempo, un esquema estructural que adopta todas las características del «sistema»saussuriano, es un indicio de la minucia con la cual Cervantes planeó la construcción y la distribución de su recopilación (y cabría quizás intentar llevar a cabo el mismo estudio para las ocho comedias, pero forse altri canterà con miglior plettro). ¿Fue algo consciente, o más bien el resultado de una intuición genial? Rafael Osuna, frente a esta disyuntiva, afirma: «la clasificación más complicada que propone Balbín es demasiado perfecta y

38. Véase la cita en la nota 2. 
armónica: de aceptarla habría, en cualquier caso, que darle a la casualidad un papel importante en el acto distribuidor» ${ }^{39}$. A nuestro parecer, la pregunta es ociosa, ya que lo que importa es el resultado que tenemos ante nuestros ojos y que nos asombra. Quizás puede haber un asomo de explicación a esta preocupación acusada hacia el aspecto estructural del conjunto si se toma en cuenta el hecho de que, como es bien sabido, Cervantes tuvo que resignarse a publicar sus ocho comedias y ocho entremeses en volumen, al no encontrar a ningún «autor» que se las representase, lo cual el mismo Cervantes hace constar desde el título de su volumen: «Ocho comedias y ocho entremeses nuevos y nunca representados». Esta circunstancia, debida a la «monarquía cómica» ejercida por Lope de Vega en aquel entonces, puede que tuviese un efecto colateral que quizás pueda explicar esta atención exacerbada hacia la estructura del conjunto. Como se recordará, en su Adjunta al Parnaso (1614), Cervantes hablando de sus obras dramáticas afirma que las dio a la imprenta «para que se vea de espacio lo que pasa apriesa, y se disimula o no se entiende cuando las representan» ${ }^{40}$. Dicho de otro modo: Cervantes, decepcionado por la fallida representación de sus obras dramáticas (que no son, como a veces se ha dicho, mero «teatro para leer», sino que están concebidas como perfectamente representables, y la mejor prueba de ello es que lo han sido y lo siguen siendo, con todo el éxito de público que sabemos), se cura en salud y hace de necesidad virtud. Puesto que no podrán verse representadas, el lector tendrá todo el tiempo para leerlas «de espacio»y, quizás, de darse cuenta de las distintas correspondencias que se entretejen entre las ocho piezas. O sea: tendrá tiempo de descubrir el «sistema» que las informa y que añade un significado adicional que no es la mera suma de los significados singulares de las ocho piezas, sino algo distinto que las engloba.

Dicho de otro modo, y apoyándonos una vez más en las teorías lingüísticas modernas, echando mano en este caso del conocido esquema de la «connotación» propuesto por Hjelmslev, podemos afirmar que las ocho piezas funcionan como el nivel «denotativo», mientras que el «sistema» se superpone a este primer nivel, revelando su aspecto connotativo.

Para decirlo con menos aridez, y con «palabras mayores», el sistema puede compararse a la rosa, que además de su forma y color, exhala su perfume, aquella rosa de la cual dio Juan Ramón Jiménez (con su acusado y acostumbrado «leísmo») una definición en su poema más breve, que es un «microsistema» de dos versos a la vez que su autodefinición:

«No le toques ya más, que así es la rosa» ${ }^{41}$.

Recibido: 5 de mayo de 2011

Aceptado: 26 de julio de 2011

39. Cf. op. cit., p. 573

40. Cit. por N. Spadaccini, ed. cit., p. 13

41. Es el poema que abre Piedra y cielo, Buenos Aires, Losada, 1968. 


\title{
Resumen
}

En este trabajo, el objetivo es el de mostrar que los ocho entremeses que Cervantes publicó en 1615 forman un «sistema», en el sentido que la lingüística moderna, en particular con de Saussure, le dio a esta palabra. A partir de un esquema temático que Rafael Balbín Lucas había publicado en 1948, y que contenía ya «in nuce» todos los elementos del sistema, nos proponemos insistir en la cohesión no sólo temática sino también estructural de la recopilación cervantina. Insistimos en particular sobre las correspondencias que se establecen entre los ocho entremeses, y esto a todos los niveles: temáticos, lingüísticos y narrativos. La unidad temática y estructural demuestra que el orden de las ocho piezas no fue casual, sino que responde a la ley del sistema, según la cual el más mínimo cambio de un elemento influye en todo el conjunto. El sistema es pues un conjunto de correspondencias, que el lector es invitado a descubrir y que tiene como consecuencia la de añadir un sentido adicional al de cada entremés tomado singularmente, o sea que funciona como el mecanismo de la connotación respecto a la denotación, según el clásico estudio de Hjelmslev.

Palabras clave: Cervantes, entremeses, sistema, cohesión, estructura, connotación.

Title: Cervantes's entremeses as a system

\begin{abstract}
This work aims to point out that Cervantes' eigth farces (entremeses), published in 1615, form a «system», according to the meaning that modern linguistics and de Saussure in particular give to this word. Starting from a thematic scheme published by Rafael Balbín Lucas in 1948, containing already «in nuce» all the elements of the system, we intend to stress the cohesion, both thematic and structural, of the Cervantes compilation. We particularly insist on the correspondences between the eight pieces that work at different levels: thematic, linguistic and narrative. Thematic and structural unity prove that the order of the eight plays was not accidental and obeys to the system's law; that is to say, the smallest change in one of th elements influences the whole of the set. Therefore the system is a collection of correspondences for the reader to discover. They also add additional meaning to each play taken individually, so it works like the mechanism of connotation respect to denotation, according to Hjelmslev's classic study.
\end{abstract}

Key words: Cervantes, entremeses, system, cohesion, structure, connotation. 